\title{
Oil and PCB Interactions on the Uptake and Excretion in Midges
}

\author{
Peter G. Meier ${ }^{1}$ and Richard R. Rediske ${ }^{2}$
}

${ }^{1}$ Department of Environmental and Industrial Health, School of Public Health, The University of Michigan, 109 Observatory, Ann Arbor, MI 48109, and ${ }^{2}$ Environmental Data Inc., 611 Cascade West Parkway, S.E., P.O. Box 6510, Grand Rapids, MI 49506

Polychlorinated biphenyls (PCBs) are highly persistent global contaminants with a broad range of long-term environmental and health effects (Fishbein 1974). Body burdens of many chlorinated aryl compounds in aquatic organisms accumulate by combinations of passive absorption directly from water or by partitioning into lipids of foods. Both routes have been shown to contribute significantly to leve1s found in fish (Stalling and Mayer 1972; Hansen et al. 1976).

Many food web organisms such as benthic invertebrates live associated with and ingest sediment as part of their feeding behavior. Although water concentrations of PCBs tend to be in the low parts per trillion range, sediments can contain levels in parts per million due to their absorptive capabilities. Thousand-fold accumulation has been demonstrated by Sanders and Chandler (1972) and Södergren and Svensson (1973) for invertebrates via absorption from water. However, accumulation from sediment feeding appears to be somewhat lower (Roberts and Meier 1982). This route of uptake needs to be further evaluated, particularly with oil and grease contaminated sediments.

Petroleum-based oils are even more ubiquitous in the sediment than PCBs. These compounds also absorb onto sedimentary particles, but at environmental concentration levels which are in excess of PCBs. Biological processes naturally contribute low concentrations of hydrocarbons to the sediment (Han et al. 1968). However, inputs from oil spills and discharges greatly exceed this background. In industrial areas such as the Detroit River, sediment oil concentrations range up to $4.8 \%$ (Hartung and Klinger 1968). Heavily polluted areas can be as high as $17.8 \%$ (Ludzack et al. 1957). In addition to their wide dispersion, oils have been shown to act as concentrators of chlorinated hydrocarbons, such as PCBS, because of their high partitioning capabilities (Hartung and K1inger 1970; Sayler and Colwell 1976). Therefore, PCBs in sediments may exist both in the absorbed and the dissolved state.

1 Correspondence and reprint requests. 
The availability and effect of PCBs in oily sediments to benthic organisms have not been examined. It is thought that the major mechanism of uptake of PCBs in the gastrointestinal tract is due to passive absorption based on partitioning into endogenous lipids. It is therefore expected that the availability of sedimentary PCBs will differ when they are absorbed directly. on particulates, as compared with PCBs which have partitioned into sedimented nonpolar solvents such as petroleum oils. In the latter case, the absorption into benthic organisms would involve competition between a two solvent system, namely sedimentary oils and endogenous lipids.

The purpose of this study was to examine the effect of sediment oil contamination on the bioaccumulation and excretion of Aroclor 1242 by the chironomid larvae Glyptotendipes barbipes Staeger. This dipteran was chosen as the test organism because it is an important fish food, and also the larva can tolerate a wide range of sediment PCB and oil concentrations. Experiments were conducted under laboratory conditions where midges were exposed to varying concentrations of Aroclor 1242 and mineral oil mixtures. An artificial substrate was chosen over natural sediment because it could be easily prepared in large quantities and accurately contaminated with both PCB and oil.

\section{MATERIALS AND METHODS}

Organisms used for stock cultures of Glyptotendipes barbipes Staeger were collected from the Ann Arbor Sewage Treatment Plant sludge lagoon system and reared according to a method described by Meier and Torres (1978). Four 38-liter rearing chambers were used. Each chamber contained 50 grams of shredded paper hand towels, 2 grams of food supplement, and 20 liters of aerated tap water. The midges were fed 1 gram of food supplement throughout their fiveweek life cycle. Fertile egg masses were transferred to new rearing chambers for each generation. The fourth generation, fourth instar larvae were analyzed for residual PCB contamination and no measurable levels were detected at an analytical limit of $0.005 \mathrm{ppm}$. Fertile egg masses from this generation were used in the experiments.

Experimental chambers were similar to those used in rearing, with the exception that polyethylene sheets containing small openings for air exchange were substituted for the plywood cover. The experimental substrate was prepared by grinding the paper towels and food supplement (15:1 ratio) to a \#20 mesh in a mechanical grinder. Fifty gram portions of the substrate were placed in a flask containing pesticide grade acetone and mixtures of Aroclor 1242 and medicinal mineral oil to give the following substrate concentrations: 


\begin{tabular}{|c|c|c|c|}
\hline & $0 \%$ & $\begin{array}{r}\text { neral } \\
0.25 \% \\
\end{array}$ & $1.0 \%$ \\
\hline Aroclor 1242 & $\begin{array}{l}0.01 \\
0.1 \\
1.0\end{array}$ & $\begin{array}{l}0.01 \\
0.1 \\
1.0\end{array}$ & $\begin{array}{l}0.01 \\
0.1 \\
1.0\end{array}$ \\
\hline
\end{tabular}

The solvent was then removed by rotary evaporation at $4^{\circ} \mathrm{C}$. Concentrations were verified by chemical analysis.

One hundred fifty grams of each substrate concentration were transferred to duplicate test chambers and allowed to equilibrate one week. Analyses conducted on the water in each chamber verified absence of Aroclor 1242 at a level of $0.0001 \mathrm{ppm}$.

Approximately 2000 second instar midges were added to each tank. Duplicate subsamples of 50-200 organisms were removed from each tank at specified intervals and placed in glass petri plates containing uncontaminated substrate for $24 \mathrm{hrs}$. This facilitated gut cleaning of contaminated materials. Upon removal, the organisms were counted, towel dried, and weighed to the nearest tenth of a milligram on a Cahn Electro balance for wet weight determination. Each sample was then placed on filter paper and kept at $-5^{\circ} \mathrm{C}$ prior to analysis. This series of experiments represented the uptake studies.

After 24 days exposure, half of each culture was transferred to clean substrate in similar experimental chambers. Organisms were sampled at specified intervals and treated as before. This series of experiments represented excretion studies. Duration of the uptake-excretion experiments was 30 days.

Aroclor 1242 analysis was conducted by extracting the filter paper containing larvae in a micro soxhlet for 5 hours with an acetone/pentane mixture. The extract was concentrated in a micro Kuderna-Danish evaporator, passed through florisil, and reconcentrated in the presence of nonane to give a final volume of $500 \mathrm{ul}$. Sediments were extracted and cleaned up in a similar nature. Water samples were analyzed by 1iquid-liquid extraction with $15 \%$ ethy 1 ether in pentane and concentrated and cleaned up as before. PCB measurement was performed by gas-liquid chromotography on a Varian $2700 \mathrm{GC}$ equipped with a $63 \mathrm{~N}$ electron capture detector. A 6-foot glass column (1/8 in I.D.) of $5 \%$ OV-210 on Gas Chrom $Q$ (80-100 mesh) was used with a nitrogen flow of $20 \mathrm{ml} / \mathrm{min}$. Oven and injector temperatures were $200^{\circ} \mathrm{C}$ and the detector was operated at $300^{\circ} \mathrm{C}$.

Sediment oil analysis was conducted by soxhlet extraction with ethyl ether and gravimetric weight determination.

\section{RESULTS AND DISCUSSION}

Bioaccumulation experiment results are presented in Figure 1. values represent the means of duplicate samples from two separate 
(A)

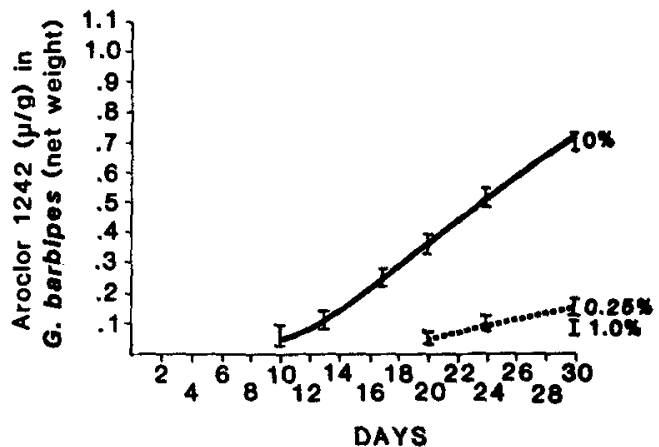

(B)

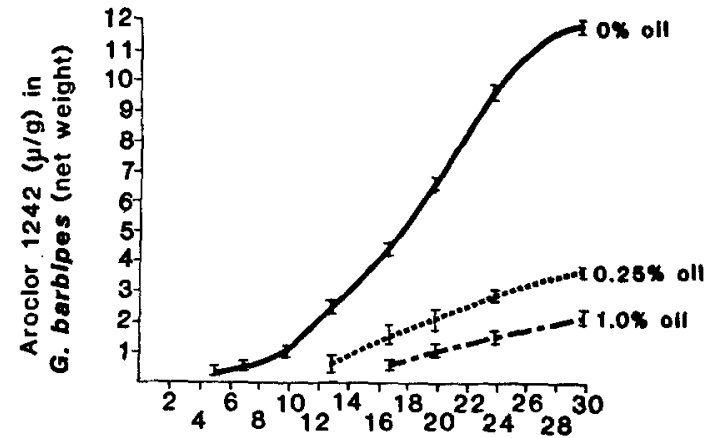

(C)

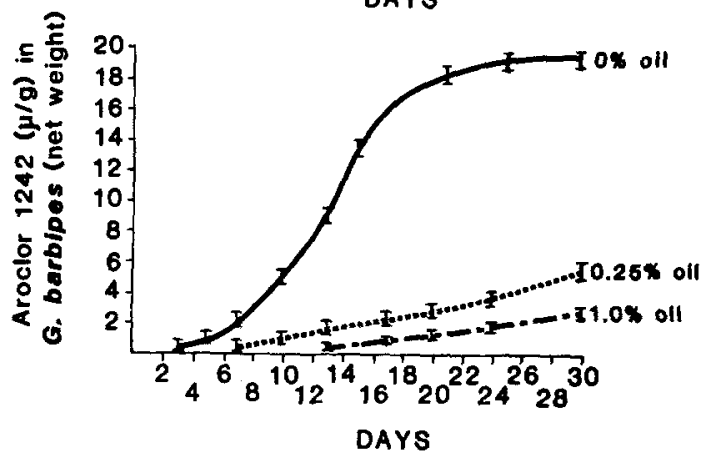

Figure 1. Accumulation of Aroclor 1242 by $G$. barbipes by substrate feeding at (A) $0.01 \mathrm{ppm},(B) \overline{0.1 \mathrm{ppm}}$, and (C) $1.0 \mathrm{ppm}$ with varying concentrations of oil. (Vertical lines denote one standard deviation.) 
experiments. In all experiments conducted, the uptake of Aroclor 1242 demonstrates a dose-dependent relationship between substrate concentration and body burden. The addition of mineral oil to the substrate resulted in a $70-80 \%$ reduction in overall uptake. The relationship between time of exposure and body burden was linear.

In the absence of oil contamination, a linear relation was observed between exposure time and body burden for $0.01 \mathrm{ppm}$ substrate level. A slight leveling was observed in the $0.1 \mathrm{ppm}$ experiments with a definite steady-state condition being reached in the $1.0 \mathrm{ppm}$ series. The organisms reached equilibrium at about 18-20 ug/g after 20 days exposure. Concentration factors were 75 and 132 for 0.01 and $0.1 \mathrm{ppm}$ in the substrate (Table 1). A concentration factor of 19.5 was determined for the $1.0 \mathrm{ppm}$ exposure.

Excretion experiments revealed that no significant amount of PCBs was excreted during the one-week period (Table 2).

The results clearly demonstrate that the chironomid larva, Glyptotendipes barbipes, can accumulate significant body burdens from substrate feeding alone. In comparing concentration factors for passive absorption from water vs feeding, the accumulation obtained in this study is considerably less. Sanders and Chandler (1972) have shown accumulation of 10,000 or more for aquatic Diptera with uptake rates being rapid and exponential. In contrast, these experiments have shown 100-fold accumulations with a gradual uptake rate. The differences can be explained on a basis of overall exposure as the amount of total PCBs a midge larvae can obtain on a daily ration. It is considerably less than the total amount it is exposed to in the water on a daily basis in a dynamic bioassay. The attainment of a steady state condition was achieved during the $1.0 \mathrm{ppm}$ experiment where a body burden of 18-20 ppm was constant during the final ten days and an equilibrium was reached between the level present in the organism and the surrounding environment. No equilibrium was reached in 0.01 and $0.1 \mathrm{ppm}$ PCB levels which suggests that the levels obtained here are not the maximum possible.

The reduction in uptake rates and overall body burden in the presence of oil contamination illustrate the effect of PCBs partitioned into oil and their availability to the benthos. Competition between the oil-PCB solvent system and endogenous lipid material in the gastrointestinal tract of the midge is of sufficient magnitude to result in a $70-80 \%$ reduction in body concentration. The competition between solvent systems is not present in oil free substrate as only molecular forces are holding PCBs to the particles. These observations are consistent with the poor absorption of fat-soluble vitamins in mammalian systems when mineral oil is substituted in the diet.

The failure of the excretion experiments to show any significant release of PCBs may be explained, on the basis that midges store fat as an energy source for flight in the last instar (Jonasson 1965). Since these experiments were conducted during the last 


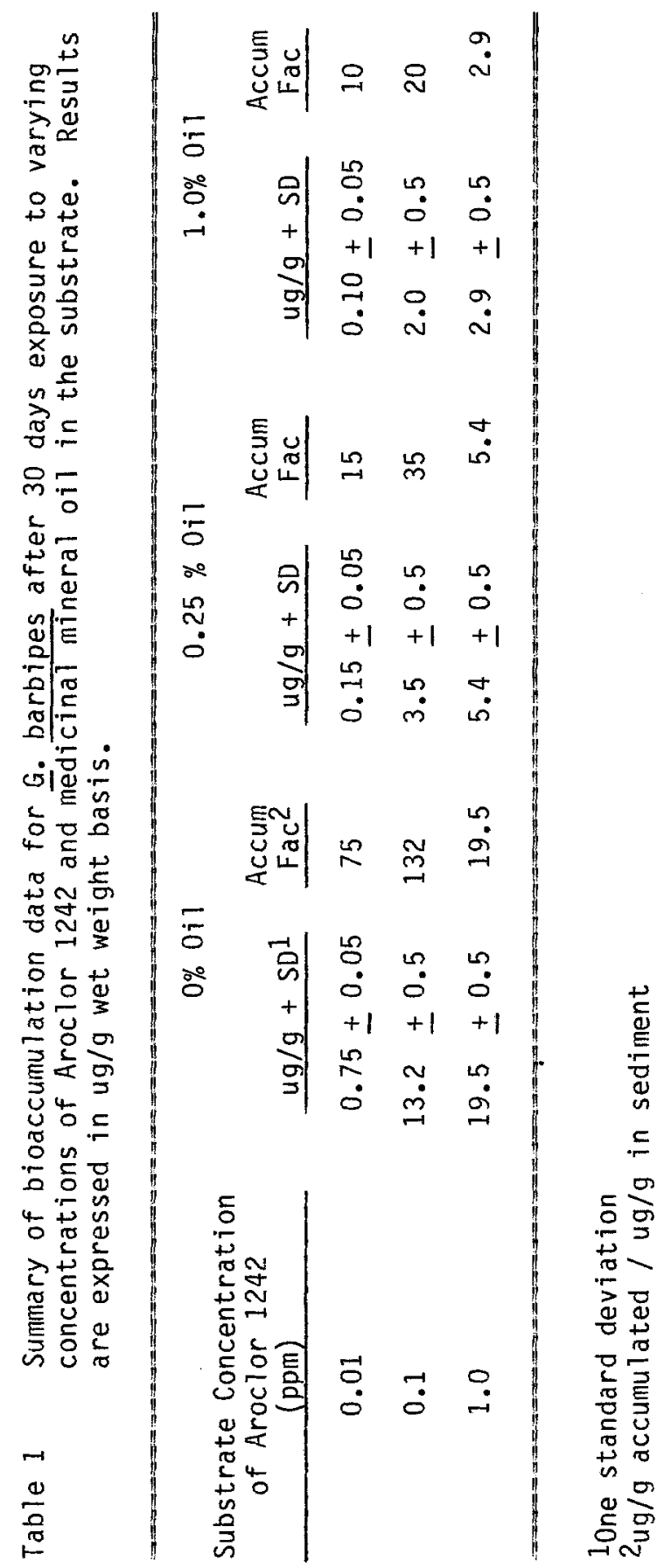




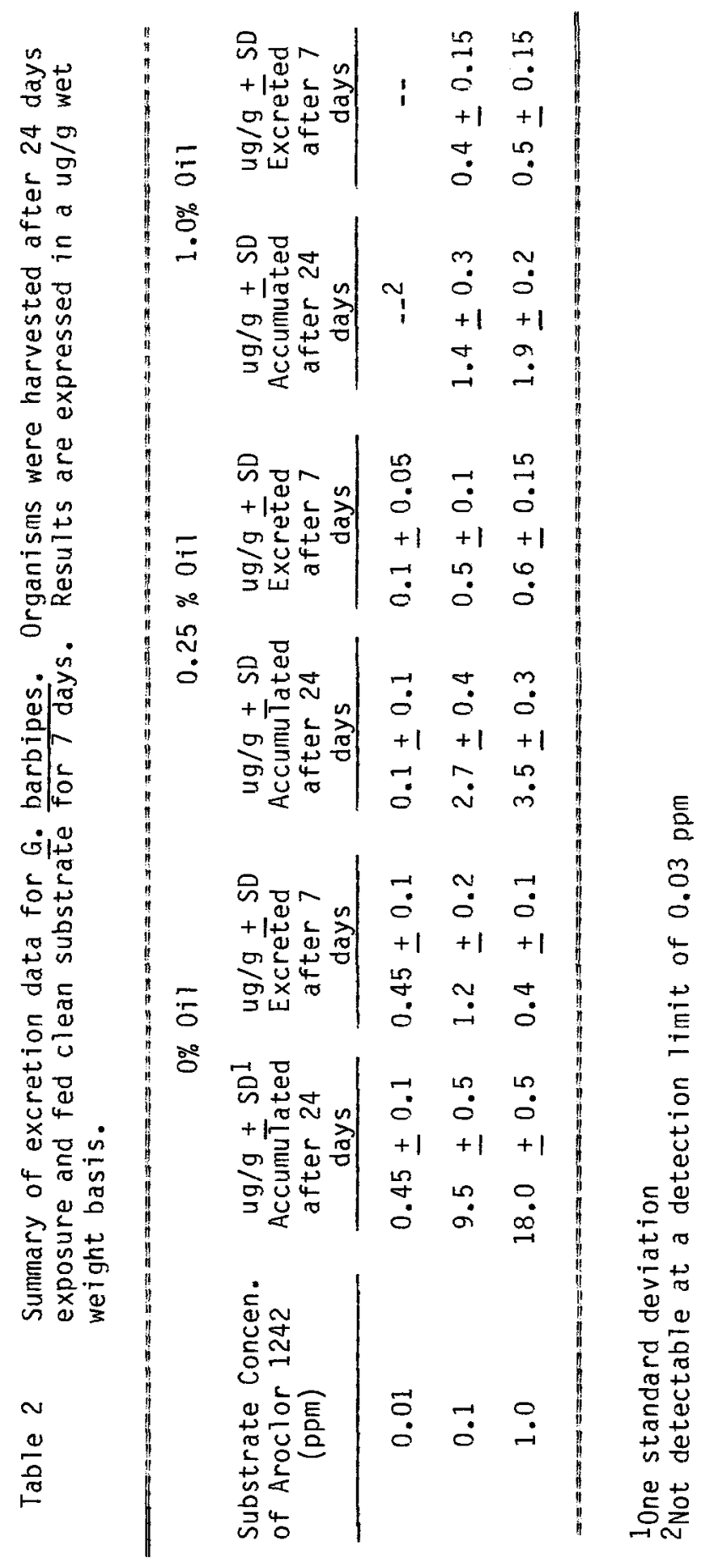


instar, the PCBs may be stored in sufficient fat reserves that little or no excretion takes place.

This study shows that food web organisms such as chironomid larvae can develop body burdens from feeding on contaminated substrate. In addition it demonstrates that oil contamination in the substrate reduces the overall availability of PCBs to benthos. This suggests potential and bio-availability. Even though it is documented that oily sediment will concentrate high levels of nonpolar materials such as PCBs, this study shows that they are also held in a less available form to bottom-feeding organisms.

Acknowledgements. This publication results from work sponsored by the Michigan Sea Grant Program with funds from the NOAA, Office of Sea Grant No. 04-M01-134; and from appropriations made by the Legislature of the State of Michigan.

\section{REFERENCES}

Fishbein, L (1974) Toxicity of chlorinated biphenyls. Annual Rev Pharmacol 14:139-156

Han J, McCarthy ED, Vanhoeven W, Calvin M, Bradley WH (1968) Organic geochemical studies II. A preliminary report on the distribution of aliphatic hydrocarbons in algae, in bacteria, and in recent lake sediment. Proc Nat Acad Sci 59(1):29-33

Hansen LG, Wiekhorst WB, Simon J (1976) Effect of dietary Aroclor 1242. on channel catfish (Ictalurus punctatus) and the selective accumulation of PCB components. J Fish Res Board Can $33(6): 1343-1352$

Hartung R, Klinger GW (1968) Sedimentation of floating oils. Papers Mich Acad Sci Arts and Letters 53:23-27

Hartung R, Klinger GW (1970) Concentration of DDT by sedimented polluting 0ils. Env Sci and Tech 4(5):407-410

Jonasson PM (1965) Factors determining population size of Chironomus anthracinus in Lake Esrom. Witt Verein Limnol B:139-162

Ludzack FJ, Ingram WM, Ettinger MB (1957) Characteristics of a stream composed of oil refinery and activated sludge effluents. Sewage Ind Wastes 29(10):1177-1189

Meier PG, Torres $H$ (1978) A modified method for rearing midges (Diptera: Chironomidae). Great Lakes Entomol 11(2):89-91

Roberts D, Meier PG (1982) A New Method for Exposing Deposit Feeders to Contaminated Sediments for Food Chain Studies. Great Lakes Entomol 15(1):59-64

Sanders HO, Chandler J (1972) Biological magnification of a polychlorinated biphenyl from water by aquatic invertebrates. Bull Env Contam and Toxicol 7(5):257-262

Sayler GS, Colwell RR (1976) Partitioning of mercury and polychlorinated biphenyl by oil, water and suspended sediment. Env Sci and Tech 110(12):1142-1145

Södergren A, Svenson BJ (1973) Uptake and accumulation of DDT and PCB by Ephemera danica (Ephemeroptera) in continuous flow systems. BuT1 Env Contam and Toxicol 9(6):345-350

Stalling DL, Mayer FL (1972) Toxicity of PCB to fish and environmental residues. Environmental Health Perspectives 1:159-164 Received October 20, 1983; accepted December 1, 1983 